ISSN electrónico: 2172-9077

https://doi.org/10.14201/fjc2017144557

\title{
LA RECUELA: ENTRE EL REMAKE Y LA SECUELA. EL CASO DE JURASSIC WORLD
}

\section{The Requel: Between the Remake and the Sequel. Jurassic World as a Case Study Analysis}

\author{
Dra. Irene RAYA BRAVO \\ Profesora interina en la Universidad de Sevilla \\ E-mail: iraya@us.es \\ (D) https://orcid.org/0000-0003-2070-303X
}

Fecha de recepción del artículo: 20/03/2017

Fecha de aceptación definitiva: 25/04/2017

\begin{abstract}
RESUMEN
Dentro del ámbito audiovisual, la expansión de los relatos se materializa a través de remakes, adaptaciones y franquicias ficcionales. En este contexto, los remakes o nuevas versiones son fórmulas muy recurrentes porque recuperan contenido familiar para la audiencia, y a la vez lo reinventan para captar la atención de nuevas generaciones.

No obstante, la fórmula del remake ha ido cambiando en el nuevo milenio, adaptándose a las nuevas tendencias narrativas. Como consecuencia del auge de la intertextualidad y el valor en alza de la nostalgia, en los últimos años se han producido numerosas películas a medio camino entre el remake y la secuela, tales como Star Wars: El despertar de la fuerza o Terminator Génesis. En particular, el objetivo de esta investigación es realizar un análisis comparativo entre Parque Jurásico y Jurassic World, pues, aunque esta última prolonga el discurso original a modo de secuela, también ofrece una reinterpretación de la primera película.
\end{abstract}

Palabras clave: remake; precuela; secuela; recuela; Jurassic Park; Jurassic World.

\begin{abstract}
In the audiovisual field, the expansion of the stories is, specifically, materialized through remakes, adaptations and franchises. In this context, the remakes or new versions are recurrent formulas because they recover familiar contents for audiences and, at the same time, they reinvent it in order to capture new generations' attention.

Nevertheless, the remake formula has been changing in the new millennium, adapting to new narrative trends. In recent years, because of the rise of intertextuality and the increasing value of nostalgia, many films have been produced halfway between the remake and the sequel, such as Star Wars. Episode VII: The Force Awakens or Terminator Genisys. In particular, the aim of this paper is to make a comparative analysis between Jurassic Park and Jurassic World because, although this last film extends the original discourse as a sequel, it also offers a reinterpretation of the first film.
\end{abstract}

Key words: remake; prequel; sequel; recuel; Jurassic Park; Jurassic World. 


\section{INTRODUCCIÓN}

La alta competencia del espectador descifrando el discurso audiovisual ha propiciado la creación de ficciones cuya comprensión aumenta si se conocen otros textos a los que se hace referencia, ya sea mediante personajes, espacios, tramas o estéticas muy identificables. En este nuevo ecosistema mediático, vinculado al contexto de la «hipermodernidad» (Lipovetsky y Charles, 2006), se establecen múltiples conexiones entre diferentes textos audiovisuales, ya sea en forma de adaptaciones, remakes o prolongaciones diegéticas, a modo de precuela o secuela.

Estas fórmulas, tan frecuentes en la historia del cine, han sufrido una evolución debido a la gran capacidad que ha adquirido el espectador para descifrar mensajes complejos e interconectados entre sí a modo de «palimpsesto», es decir, como textos que se superponen a otros y los dejan ver por transparencia (Genette, 1989, p. 495). De esa forma, en algunos casos de la cinematografía reciente puede comprobarse cómo la tradicional secuela se convierte en una especie de reescritura del texto original, acercándose, en estilo y contenido, al propio remake, pero sin llegar a contar exactamente la misma historia. Precisamente, de la fusión de secuela y remake proviene el término recuela, cuyo origen y significado se desarrolla a lo largo de esta investigación, y que también se vincula con otras fórmulas recientes de reescritura como el reboot.

Con la finalidad de ofrecer un estudio de caso, en el presente artículo se realiza un análisis comparativo entre dos películas que se inscriben en una misma franquicia cinematográfica de éxito, viendo así cómo los elementos que las vinculan trascienden al mismo tiempo el concepto clásico de secuela y de remake, convirtiéndose en una recuela. El primer filme escogido es Parque Jurásico (Jurassic Park, Steven Spielberg, 1993), considerado un producto simbólico en cuanto a revolución digital se refiere, porque es la primera película en la que aparecen unos personajes íntegramente generados por ordenador (Riambau, 2011, p. 8). La segunda película con la que se compara es Jurrasic World (Colin Trevorrow, 2015), tercera secuela con respecto al producto original y en la que la acción vuelve a centrarse en el espacio principal, la famosa isla Nublar. Para la realización del estudio se emplean conceptos procedentes de la narrativa audiovisual, que sirven para analizar tanto el contenido como la forma, y se observan además en relación a su contexto concreto de producción, entrando dentro del ámbito de los estudios culturales.

\section{MARCO DE REFERENCIA}

\subsection{EL CONCEPTO DE ORIGINALIDAD EN LA HIPERMODERNIDAD}

Cuando se comenta que se ha producido la entrada en un nuevo paradigma mediático, realmente se está hablando sobre la superación de la posmodernidad, o al menos, sobre el comienzo de una nueva fase de la misma. El concepto de «hipermodernidad», acuñado por Gilles Lipovetsky y Sébastien Charles, se refiere a ese nuevo momento histórico en el que triunfa el paradigma individualista de manera que «las grandes certezas ideológicas se borran [...] a favor de las singularidades subjetivas» (2006, p. 33), en un proceso de desmitificación que ha afectado de forma simultánea a todos los territorios vitales. Los autores disertan sobre las cualidades de esta época particular y encuentran un denominador común en todos los ámbitos: «Hipercapitalismo, hiperclase, hiperpotencia, hiperterrorismo, hiperindividualismo, hipermercado, hipertexto, ¿Habrá algo que no sea hiper?» (p. 55).

Como consecuencia, la aparición de un nuevo contexto ha propiciado múltiples cambios, de modo que lo «hiper» transforma todos los campos, tal y como sucede con las manifestaciones artísticas. Sin ninguna duda, la evolución del concepto originalidad ha sido una de las principales transformaciones que se han producido en el terreno cultural, pues se ha sustituido el antiguo canon de lo inédito 
como único criterio de calidad. Siguiendo esa línea de pensamiento, la referencialidad, las conexiones o la integración de obras audiovisuales en macroestructuras discursivas superiores se han revalorizado y se han considerado como síntomas del nuevo contexto audiovisual. No obstante, es posible observar este fenómeno desde dos miradas contrapuestas:

Por un lado, la dependencia entre textos y la constante mezcla de elementos narrativos puede considerarse como la consecuencia natural del agotamiento de fórmulas originales. El reciclaje de «recetas» puede interpretarse de forma negativa, como el desgaste consecuente de la escasa capacidad de innovación de las entidades emisoras. Dicha idea proviene de la teoría crítica, que incluso consideraba que los géneros cinematográficos crean unos estereotipos que impiden que la audiencia sea creativa y que se modifiquen sus ideas preconcebidas mediante el progreso de su experiencia (Wolf, 1987, p. 102). Desde esta perspectiva, además del uso de géneros, la creación de secuelas, adaptaciones o remakes se fundamenta en el cansancio creativo atribuido a las productoras de cine.

Por otro lado, se puede interpretar que la intertextualidad, el revisionismo, la creación de universos infinitos y la hibridación genérica son síntomas que evidencian la madurez de los nuevos productos de ficción. Desde una óptica actual, este rechazo hacia el reciclaje encierra una concepción simplista y no contempla la renovación y la incesante evolución del concepto «originalidad» que se vive desde finales del siglo XX. Autores como Balló y Pérez (2005) defienden que el mito del valor único de la novedad debe ser abandonado, pues las ficciones de la repetición como las series o las sagas, poseen originalidad por su potencialidad para desplegarse y vincularse con otros relatos y universos narrativos. Eco (2012) habla a este respecto de «dialogismo intertextual», definiéndolo como una práctica propia de la posmodernidad, entrando en el «juego irónico sobre la intertextualidad», a través de lo que él llama, la introducción de la «cita irónica del topos», es decir, la repetición de lugares comunes que solo son descifrados por el espectador conocedor del texto previo. Además de ser intertextuales son propuestas autoconscientes de sus vínculos con otros textos concretos, o con amplios sistemas discursivos, por lo que exigen al espectador ese conocimiento previo, sabiendo que parte de su encanto reside en esa complicidad que comparten con el público. El autor cita precisamente ejemplos clásicos del cine como El imperio contrataca (Star Wars. Episode V: The Empire Strikes Back, Irvin Kershner, 1980), En busca del arca perdida (Indiana Jones: Raiders of the Lost Ark, Steven Spielberg, 1981) y E.T. El extraterrestre (E.T. the Extra-Terrestrial, Steven Spielberg, 1982), especificando que introducen alusiones específicas cuyo reconocimiento aumenta el interés de la audiencia; el escritor resalta además cómo «un fenómeno semejante era típico en tiempos de un arte experimental que presuponía un lector modelo bastante refinado culturalmente», resultando cuanto menos significativo que se haya introducido como práctica habitual en la comunicación de masas.

Recogiendo la herencia de Eco, la investigadora Eva Pujadas (2011, p. 55) lo sintetiza con las siguientes palabras: «Allí donde unos niegan la calidad por tratarse de obras seriales y repetitivas, otros espectadores pueden apreciar el matiz de la cita, la referencia cruzada, etc. y por ello apreciar su calidad». Algunos textos audiovisuales incluso se construyen mediante guiños y alusiones a otros discursos, de forma que la «hiperconsciencia» se ha convertido en un emblema de la cultura popular postmoderna, basada en diferentes clases de autorreflexividad (Collins, 1992, p. 335). En definitiva, las continuas conexiones a otros textos cuando se produce ese reconocimiento por parte del público se ha convertido en parte del placer del visionado, lo que también requiere una mayor implicación por parte del espectador (Gwenllian-Jones y Pearson, 2004; Mittell, 2004, Eco, 2012). El académico estadounidense Henry Jenkins se une a esta línea de pensamiento, defendiendo que más que observar la posmodernidad como un escenario de significados vacíos, tiene más sentido analizar las obras que se producen en este momento como parte de un collage o pastiche. El autor alega que en la mente del 
espectador se va instalando un «palacio de la memoria» en el que se van añadiendo capas complejas de significado y asociación de ideas (2007, p. 44). Desde esta perspectiva, la «nueva originalidad» es un fenómeno que puede entenderse como ejemplo de la riqueza sintáctica y semántica que puede encontrarse actualmente en un texto televisivo, contemplado este como un nuevo eslabón de la trayectoria histórica y artística del medio.

\subsection{SECUELAS Y REMAKES}

Cuando un texto parte de otro tiene la ventaja de contar con un referente que le resulta conocido al espectador, de manera que el acceso a la nueva propuesta no le resulta ajeno o dificultoso. La familiaridad, al igual que la serialidad, se ha convertido en un valor seguro que garantiza la longevidad de los universos narrativos.

Una de las estrategias más comunes que se emplean en la expansión de un relato audiovisual es la narración de acontecimientos que ocurren antes, a la vez, o posteriormente a los sucedidos en un determinado texto. Desde una perspectiva narrativa, las prolongaciones de la diégesis amplían el relato, ya sea hacia atrás (retrospectivas), hacia delante (prospectivas), describiendo acontecimientos paralelos (simultáneas) o incluso posibilidades diferentes del relato (alternativas). Genette (1989, pp. 253254) diferencia entre continuación y prolongación matizando que la primera finaliza un texto en suspensión mientras que esta última no continúa una obra para llevarla a su término, sino que su objetivo es conducirla más allá de lo que inicialmente se consideraba como su fin, siendo una práctica habitual para la reproducción de un éxito. La tendencia actual en el mercado audiovisual es hacia la prolongación, porque el objetivo financiero es ampliar los márgenes de un relato siempre que este haya resultado interesante para el público. De esta forma, aunque se parta de una percepción narrativa del concepto teórico de prolongación diegética, es ineludible contemplarla como una estrategia de producción, pues esta óptica es la que finalmente determina la evolución de un discurso fuera de sus márgenes originales. Las prolongaciones diegéticas prospectivas, denominadas secuelas desde el punto de vista de la producción, presuponen la existencia de un universo rico con la capacidad de originar posteriores eventos que se desvíen de la premisa original.

Por otro lado, la realización de nuevas versiones o remakes suele ser una fuente argumental prolífica en el mercado cinematográfico porque se reutilizan personajes, espacios y relatos conocidos por el público actualizando su representación. Aunque los remakes se vinculan al ámbito audiovisual, lo cierto es que es un hábito muy antiguo vinculado al mundo del arte en general, pues se realizaba tanto en el ámbito de las artes plásticas como en la literatura (Riambau, 2011, p. 255). No obstante, sí que es cierto que la creación de nuevas versiones se ha convertido en la actualidad en una práctica muy habitual tanto en cine como en televisión, de forma que estos remakes se comprenden como "productos industriales», con la capacidad de proveer modelos replicables que limitan, en cierta medida, el riesgo financiero (Verevis, 2006, p. 3). Durante el visionado de los remakes, parte de la emoción y del placer que obtiene el espectador proviene del saber superior de la historia, lo que coloca al público en una posición privilegiada con respecto a los personajes (Visa Barbosa, 2008). Las adaptaciones, como tal, pueden contemplarse como nuevas versiones de un producto original, pero la diferencia entre ambas es que las primeras requieren un cambio de formato, con la consecuente adaptación al lenguaje y los códigos del nuevo medio, mientras que en las nuevas versiones no se produce esa permuta.

Históricamente, el término se ha asociado peyorativamente a un hábito de la industria cinematográfica norteamericana ante la escasez de ideas nuevas y originales, convirtiéndose además en un fenómeno cada vez más frecuente en el ámbito audiovisual de las últimas décadas. No obstante, la proliferación de remakes recientes también está unida al concepto de intertextualidad en un sentido amplio 
(Stam, 2001; Verevis, 2006), pues al igual que sucede con los géneros, también están vinculados a las expectativas y el conocimiento de la audiencia, introduciendo referencias y alusiones (Verevis, 2006, p. 23), en una especie de juego nostálgico que, a la vez que recupera el texto original, construye uno nuevo.

En ocasiones, el objetivo de esas nuevas versiones no es imitar el producto original, sino que se produce una reinvención del concepto primigenio, conservando solo algunos detalles clave de la antigua trama. Estos remakes construyen con los mismos elementos de partida un texto divergente al primigenio, entrando en el terreno del reimagining o, más popular en el ámbito cinematográfico, el reboot. Dicho término se refiere al proceso de reiniciar un producto fílmico existente regresando a su punto de origen, lo que se ha convertido en una técnica utilizada con frecuencia para revivir el interés en franquicias como las protagonizadas por personajes como Batman a James Bond (Tryon, 2013, p. 432).

\subsection{LA RECUELA}

Tal y como se ha mencionado previamente, en la era hipermoderna los textos adquieren un nuevo valor por la interpretación del público, cuyo «palacio de la memoria» relaciona diversos productos que precisamente son estimados por las interconexiones que establecen. La audiencia disfruta con las referencias y es capaz de descifrar complejas capas de interconexiones, compartiendo ese conocimiento a través de las redes sociales y utilizando además conceptos narrativos que previamente estaban más limitados al ámbito académico. Por esta razón, algunos términos como remakes, spin-off o cliffhanger se convierten en nociones habituales dentro de las redes sociales y se consideran tema de debate en blogs y foros.

En ocasiones, incluso introducen tópicos o fenómenos que son acogidos en el ámbito académico, como sucede en este caso con el concepto de «recuela». Para entender su significado es necesario recurrir a la fuente donde se origina, que es la red social Twitter. En diciembre de 2015, el director español de cine Nacho Vigalondo publica el siguiente tuit en referencia a este fenómeno: «Esta extraña cultura de la nostalgia masiva ha creado un género propio: La Recuela, remake y secuela a la vez» ${ }^{1}$. Dicho comentario es retomado por otros internautas, utilizándose para referirse a producciones que prolongan los confines del texto original, pero guardando una semejanza importante con respecto al mismo. Los usuarios de las redes utilizan el concepto para referirse especialmente a la nueva entrega de Star Wars: El despertar de la fuerza (Star Wars. Episode VII: The Force Awakens, J. J. Abrams, 2015)², el episodio siete de la famosa saga de ciencia ficción. El término recuela será rescatado en otros medios como blogs ${ }^{3}$ que lo emplean para definir otros títulos con espíritu revisionista como Star Trek (J. J. Abrams, 2009), Mad Max: Furia en la carretera (Mad Max: Fury Road, George Miller, 2015), Terminator Génesis (Terminator Genisys, Alan Taylor, 2015) y Jurrasic World. También el conocido sitio web Urban Dictionary ${ }^{4}$ recoge una entrada con esta acepción, explicando que el concepto define aquellas secuelas que se encuentran a medio camino entre la secuela, el reboot y el remake, y aportando además los mismos ejemplos previa-

\footnotetext{
1 @vigalondo $(2015,12,19)$. Recuperado de https://twitter.com/vigalondo/status/6783573355601897472.

2 Algunos tuits relevantes: @La_Ruina (2015,12,19), @uncientovolando (2015,12, 20), @alvargonauta92 (2015, 12, 22), @DMPguionista $(2015,12,27)$, Timeline completo recuperado de:

https://twitter.com/search?q=RECUELA\%20VIGALONDO\&src=typd.

${ }^{3}$ Vázquez Luna, N. (2016,1, 23). Blockbusters en tiempos de recuela. Recuperado de: http://www.lallaveazul.es/?p=326.

Tonder, M. (2016, 2, 9). Star Wars El Despertar de la Fuerza, la RECUEL A (reboot-secuela. Recuperado de:

http://pelisyjuegossegunyo.blogspot.com.es/2016/02/star-wars-force-awakensel-despertar-de.html.

${ }^{4}$ Definición proporcionada por el usuario h'biki (2016, 3, 30). Recuperado de:

http://www.urbandictionary.com/author.php?author $=\mathrm{h} \% 27 \mathrm{biki}$.
} 
mente mencionados. De esta manera, las internautas pretenden expresar que son conscientes del homenaje explícito que dichas películas realizan a las obras originales y que, de cierta manera, aunque dichas producciones avanzan la historia, también están reescribiendo el relato original. Siguiendo esta reflexión, puede comprobarse cómo el concepto de recuela guarda ciertas conexiones con el concepto de reboot, ya que una de sus principales características es que está reimaginando el texto original. No obstante, a diferencia del reboot, la recuela cuenta una nueva historia, y aunque guarde múltiples conexiones con la anterior obra, realmente está avanzando el discurso y expandiendo la diégesis original. En esta línea, puede interpretarse que tanto el reboot como la recuela son especializaciones o variantes del remake, pues implican una reescritura del texto primigenio a la vez que generan nuevos significados.

Sin ninguna duda, estas películas conectan con una tendencia reciente, instaurada tanto en cine como en televisión, que se basa en el rescate nostálgico de contenidos. Su objetivo es la evocación de textos audiovisuales de culto mediante la creación de nuevas producciones que emulan su espíritu. En esta línea, algunas películas familiares de los 80 como E.T., Los Gremlins (Gremlins, Richard Donner, 1984) o Los Goonies (The Goonies, Richard Donner, 1985) son rememoradas en nuevas producciones que se contextualizan en los mismos años y con las que guardan semejanzas temáticas, tales como Super 8 (J. J. Abrams, 2011) o la serie televisiva Stranger Things (Netflix, 2016- ). Asimismo, en televisión se está produciendo el lanzamiento de series a modo de revival, emitiendo secuelas de series populares de los años 80 y 90, como muestran los recientes estrenos de Madres forzosas (Fuller House, Netflix, 2016- ), Expediente X (The X Files, Fox, 2016- ) o Las cuatro estaciones de las chicas Gilmore (Gilmore Girls: A Year in the Life, Netflix, 2016- ).

\subsubsection{LA SAGA JURÁSICA, EL CONTEXTO DISCURSIVO DE JURASSIC WORLD}

Entre los ejemplos cinematográficos que los internautas identifican como recuela se encuentra $J u$ rassic World, el caso de estudio seleccionado para el presente artículo. Antes de introducir el análisis de la película, es necesario hacer una breve contextualización del universo discursivo en el que se inserta, pues pertenece a un mundo narrativo muy popular dentro de la memoria colectiva.

Parque Jurásico es la primera obra cinematográfica que origina esta gran saga, suponiendo un éxito absoluto de audiencia, ya que alcanza una recaudación superior a los mil millones de dólares ${ }^{5}$. La película está basada en una novela de Michael Crichton y cuenta cómo se trata de construir un parque de atracciones con dinosaurios clonados. La iniciativa parte del millonario John Hammond (Richard Attenborough), que ha diseño dicho espacio de ocio en la isla Nublar (Costa Rica) y que necesita la aprobación de expertos que aseguren la viabilidad del parque. Para ello cuenta con la visita de dos paleontólogos, el doctor Alan Grant (Sam Neill) y la doctora Ellie Sattler (Laura Dern), y un matemático, el Doctor Ian Malcolm (Jeff Goldblum); los propios nietos de Hammond, Tim y Lex Murphy (Joseph Mazzello y Ariana Richards), también se encuentran de visita en el parque cuando un fallo humano desata la liberación de los dinosaurios en el recinto. Esta premisa cautivó a millones de espectadores alrededor del mundo, porque a la vez que Steven Spielberg introducía innovadores efectos especiales, desarrollaba una gran historia de aventuras en la que se reflexiona sobre el papel de la familia (Sánchez-Escalonilla, 2004; Riambau, 2011).

Durante la siguiente década se desarrollan dos secuelas a modo de prolongación diegética de la historia original: El mundo perdido: Jurassic Park (The Lost Word: Jurassic Park, Steven Spielberg, 1997) y Parque Jurásico III (Jurassic Park III, Joe Johnston, 2001). Además de rentabilizar el enorme éxito de Parque Jurásico, uno de los objetivos principales de realizar una secuela de un producto tan icónico era

\footnotetext{
${ }^{5}$ Datos de recaudación recuperados de: http://www.boxofficemojo.com/movies/?id=jurassicpark.htm.
} 
mejorar los efectos especiales con respecto al filme original, intentando «ofrecer al público un espectáculo de dinosaurios técnicamente más perfecto que en la película de 1992» (Sánchez-Escalonilla, 2004, p. 331). En la primera secuela, también basada en una novela de Michael Crichton, la mayor parte de la acción se desarrolla en la isla Sorna, un espacio habitado por dinosaurios en libertad tras el desastre de Nublar. A modo de spin-off, la película está protagonizada por el doctor Ian Malcolm, que viaja a la isla junto a su pareja, la paleontóloga Sarah Harding (Julianne Moore) para realizar un informe que impida la creación de un nuevo parque de atracciones en San Diego. En un intento fallido de traslado a la ciudad, los dinosaurios son finalmente revelados a la opinión pública, lo que conecta con el tercer largometraje, en donde el mundo ya conoce la existencia de estos seres creados en laboratorio por InGen; en esta nueva entrega, otro de los personajes principales de la primera película, el Doctor Alan Grant, es manipulado para volver a la zona junto a una familia que consigue salvarse gracias a los conocimientos y la experiencia del Doctor.

Más de veinte años después del estreno de la primera entrega, y con una diferencia de 14 años con respecto a la última secuela, se estrena Jurrasic World, convirtiéndose en ese momento en el mejor estreno de fin de semana de la historia en Estados Unidos, y alcanzando en esos dos días una recaudación superior a los 208 millones de dólares ${ }^{6}$. La película respeta el lapso temporal real y cuenta cómo, veintidós años después de la primera experiencia fallida, finalmente se ha conseguido abrir el parque temático soñado por John Hammond en la propia isla Nublar. Tal y como suponía Hammond, el centro de ocio se ha convertido en un espacio recreativo de éxito, por lo que cada año debe procurar innovadoras atracciones para seguir manteniendo el número de visitantes. Por esta razón, la nueva jefa de operaciones, la Doctora Claire Dearing (Bryce Dallas Howard), encarga al jefe de laboratorio la creación de una nueva especie híbrida, el Indominus Rex, que siga atrayendo el interés de los turistas. El nuevo dueño del parque, Simon Masrani, impresionado por el nuevo dinosaurio, decide contactar con Owen Grady (Chris Pratt), un exmilitar que entrena a los Velociraptores, para que valore el riesgo que origina su existencia. Cuando el Indominus Rex escapa sembrando el caos, la trama se complica porque los sobrinos de Dearing, Zach y Gray Mitchell (Nick Robinson y Ty Simpkins), están visitando el parque y porque, además, Grady sufre presiones del sector militar para usar a los raptores como arma.

\section{Metodología y objetivos}

El objetivo del presente artículo es realizar un análisis comparativo entre Parque Jurásico y Jurassic World, observando cómo la segunda película prolonga el discurso madre y, a la vez, reinterpreta el texto primigenio. Para el desarrollo del estudio analítico se emplean conceptos propios de la narrativa audiovisual, prestando también especial atención a las claves que ofrecen los estudios culturales en cuanto a contextualización histórica del momento de producción. En definitiva, en la comparación narrativa realizada se distinguen las siguientes fases:

1. En primer lugar, se examinan las semejanzas entre los «existentes», entendidos como aquellos componentes de la narración que se presentan en el interior de la historia (seres humanos, objetos, animales, paisajes, construcciones...) definiéndola, y que a su vez se articulan en dos categorías, «los personajes» y «los ambientes»; los primeros hacen que se produzcan los hechos y los segundos delimitan los decorados y las coordenadas espacio temporales en las que se mueven los personajes (Casetti y di Chio, 1991, pp. 173-177). Los personajes y los ambientes también aportan claves sobre la actualización del relato, pues la diferencia de más de veinte años entre ambas producciones establece ineludibles diferencias de contexto.

\footnotetext{
${ }^{6}$ Datos de recaudación recuperados de: http://www.imdb.com/title/tt0369610/business?ref =tt dt bus.
} 
2. Asimismo, se contemplan las coincidencias narrativas a nivel estructural según los ciclos del relato (Bremond, 1970), y también la repetición de roles y situaciones. Igualmente, se enumeran aquellas cualidades que designan la ampliación del discurso como prolongación diegética prospectiva, viendo en qué sentido continua la progresión del relato original.

3. Seguidamente se revisan las referencias intertextuales explícitas que se producen entre ambos filmes. Se presta especial atención a los ejemplos de «intertextualidad como alusión» en los que la conexión sea muy fuerte, entendiendo que son aquellas referencias «cuya plena comprensión supone la percepción de su relación con otro enunciado al que remite necesariamente» (Genette, 1989, p. 10).

4. Por último, se señalan los temas comunes, es decir, los contenidos de la segunda película que evocan el espíritu de la primera entrega. El propósito es comprobar si la nueva secuela funciona como «ficción de la repetición» (Balló y Pérez, 2005), observando en qué medida adapta y reinterpreta el mismo mensaje a modo de remake.

Mediante estas fases de análisis se pretenden demostrar las coincidencias en cuanto a estructura y temática, viendo también en qué medida son consecuencia de elecciones casuales o intencionales.

\section{RESULTADOS DEL ANÁLISIS COMPARATIVO}

Empezando por el análisis de los existentes, si se centra la atención en los personajes principales de Jurassic World, es reseñable cómo, a diferencia de las otras secuelas, en donde aparecen protagonistas como el Dr. Malcom y Hammond en El mundo perdido: Jurassic Park o el Dr. Grant en Parque Jurásico III, en este caso apenas se rescatan caracteres $^{7}$ de la primera entrega. No obstante, puede comprobarse que sí se repiten muchos roles, sobre todo en lo concerniente a su función en el relato. De nuevo, gran parte de la película se centra en la salvación de dos niños, pues si en Parque Jurásico eran los nietos del gerente John Hammond, en esta ocasión son los sobrinos de la doctora Dearing, jefa de operaciones del parque. En ambas situaciones, los niños son protegidos por figuras familiares que además son, en gran medida, culpables del caos, y también por otros adultos desconocidos que toman esa responsabilidad. Los auténticos progenitores de los niños están ausentes en sendos casos, inmersos además en respectivos procesos de divorcio, pero lo significativo es que los adultos que los rodean asumen dicho compromiso arriesgando sus propias vidas cuando se desencadena el peligro. En todas las entregas de la saga se explora la paternidad y el concepto de familia (Sánchez-Escalonilla, 2004), tanto en humanos como en dinosaurios, lo que conecta a las especies con su responsabilidad primaria como seres vivos.

Como se ha mencionado previamente, la obsesión de los gerentes por cumplir sus objetivos (Hammond quiere cumplir su sueño a toda costa, mientras que la Doctora Dearing quiere mantener la rentabilidad económica) acaba siendo su gran error. Estas obsesiones son confrontadas por otros protagonistas de la historia: en el primer producto por parte de los Doctores Grant, Sattler y Malcolm, y en el caso de Jurassic World se personifica en la figura del ex militar Owen Grady ${ }^{8}$; ante la obstinación de Hammond y Dearing de manipular las leyes de la naturaleza, Grant, Sattlet, Malcolm y Grady, tratan de mostrar la imprevisibilidad de dicha empresa y la necesidad de tratar a los dinosaurios con respeto y cautela.

En Jurassic World se produce el retorno al espacio original, la isla Nublar, pero a la vez se ha producido una reconstrucción del ambiente, pues la isla finalmente se ha convertido en el parque de

\footnotetext{
${ }^{7}$ La principal conexión es el Dr. Henry Wu, genetista en el primer parque y también en el segundo.

${ }^{8}$ Los fans de la saga especulan sobre la posibilidad, ni desmentida ni confirmada por los creadores, de que Owen Grady aparezca al principio de la primera película en el papel del «chico voluntario» (acreditado como Volunteer Boy). Este personaje conoce al doctor Grant durante una excavación y él es quien le inculca la necesidad de respetar a los dinosaurios.
} 
atracciones soñado por Hammond en Parque Jurásico. La edificación del gigantesco espacio lúdico, que en el primer filme resultaba una completa utopía, se ha convertido aquí en una realidad. De hecho, la necesidad de sorprender a unos visitantes cada vez más acostumbrados a los dinosaurios motiva la experimentación genética, con la finalidad de encontrar un espécimen auténticamente amenazante (Indominus Rex) que siga sorprendiendo a los turistas. En ese sentido, ambas películas resultan alegóricas con respecto a su contexto histórico de producción, pues mientras Parque Jurásico representa el inicio de la revolución digital en el inicio de la década de los 90, Jurassic Word simboliza la habituación, incluso el hastío del público, hacia este tipo de películas. A este respecto, el investigador Esteve Riambau hace la siguiente observación con respecto a Parque Jurásico:

Los planos de CGI ocupan apenas seis minutos y medio de las poco más de dos horas del metraje de Jurassic Park. Y, sin embargo, estas decisivas imágenes delimitan un antes y un después en la historia del cine. [...] Jurassic Park desarrolló una técnica que, desde 1993, nutre buena parte de las escenas más espectaculares del cine contemporáneo. Y lo hizo, además, por las exigencias de un guion que plantea, precisamente, la vinculación del pasado con el futuro, la resucitación de viejas especies animales gracias a modernas tecnologías genéticas, y la reflexión sobre los límites éticos entre la ciencia y el ocio. (2011, p. 76).

Más concretamente, Riambau se refiere a que, a pesar de que la mayor parte de los dinosaurios de la película son figuras animatrónicas de tamaño real y manejadas por control remoto, la secuencia de la estampida de los Gallimimus, que sí es completamente virtual, marca un hito trascendental. El espectador no había visto antes algo así en la gran pantalla, además vinculado a un guion que reflexiona precisamente sobre la relación entre la ciencia y lo imposible. Con Jurassic Word es imposible crear tal nivel de expectación porque el espectador ya ha consumido, durante más de dos décadas, películas básicamente desarrolladas a través de imágenes generadas por ordenador. Esta secuela se integra en una era marcada por la «estética del espectáculo» (Darley, 2000; Isaacs, 2008) y el desarrollo técnico, en donde a menudo el contenido se relega a segundo plano y se le otorga mayor importancia al acabado visual, convirtiéndose la propia tecnología en el mensaje (Darley, 2000, p. 53).

En relación con las ubicaciones concretas, en Jurassic Word se reproducen zonas que continúan teniendo el mismo peso en la trama. Por un lado, de nuevo la sala de control del parque acapara gran protagonismo, aunque a diferencia de la primera película, se trata de un escenario mucho más amplio con un mayor número de técnicos trabajando. Acorde a las tendencias de la hipermodernidad, el espacio se ha magnificado, lo que simula un mejor dominio de la situación y más capacidad de respuesta. No obstante, en ambas producciones se pone de manifiesto que cualquier intento de controlar la naturaleza desemboca en el caos, a pesar de la eficiencia y el desarrollo tecnológico implementado. Asimismo, la sala de control de Jurassic World evoca el espíritu voyeurista del reality show, conectando con uno de los formatos más populares del nuevo milenio, pues los trabajadores de la misma también son espectadores del inminente desastre, viviendo los acontecimientos desde una cierta distancia de seguridad. Si se concibe a los propios técnicos como espectadores, entre ellos el modelo ideal lo ejemplifica el técnico Lowery Cruthers (Jake Johnson), ya que desde un principio se declara fan del primer y malogrado parque de atracciones. La introducción del personaje fan de Parque Jurásico dentro del propio discurso conecta con las prácticas de consumo del siglo XXI, jugando con las conexiones entre realidad y ficción, es decir, entre el fan de la primera película y el admirador del originario parque de atracciones. Además, Lowery es la conexión generacional entre ambas películas, pues él mismo comenta la autenticidad del primer parque, viste una camiseta promocional del mismo (adquirida a pre- 
cio desorbitado por eBay) y decora su escritorio con dinosaurios de juguete. La introducción de este personaje ejemplifica el gancho comercial de la secuela, pues además de atraer a un público general, la película quiere conectar directamente con la generación que representa Lowery Cruthers; por esta razón, en una especie de juego metatextual, cuando el nuevo dueño del parque Simon Masrani (Irrfan Khan) visita las instalaciones del Indominus Rex exclama «los que tendrán pesadillas serán los padres», aludiendo a que esa generación de niños impactados por la primera película seguirán disfrutando de esta entrega con la misma intensidad. Observando la significación de otros escenarios, la misma sensación de hiperbolización que produce la sala de control se repite con el laboratorio, que también es mucho más amplio y sofisticado en relación al producto original, contando asimismo con un mayor número de personal.

Desde la perspectiva de la organización del relato, ambas películas guardan una estructura similar de principio a fin. Siguiendo su ciclo narrativo (Bremond, 1970), se identifica cómo ambas películas comienzan con una situación inicial satisfactoria, pues se muestra la existencia de un parque temático único y casi mágico donde dinosaurios y humanos parecen coexistir en relativa estabilidad; inevitablemente, este estado sufre una degradación cuando se muestra que el control del parque tiene sus limitaciones, lo que acaba evolucionando hacia el caos y el descontrol absoluto, es decir, el estado de deficiencia. Finalmente, la situación se repara, lo que se ejemplifica con la salvación de los protagonistas, aunque si bien es cierto que el estado general es satisfactorio, también se pone de manifiesto la incapacidad para restaurar el estado inicial, pues ambos parques acaban completamente destruidos. Además, ambas películas introducen una secuencia, a modo de prólogo, que alerta al espectador sobre los peligros que pueden encontrarse en el idílico parque: en la primera, se muestra un accidente laboral con un dinosaurio que ejemplifica el peligro que esconde el idílico centro recreativo; en el segundo caso, como el espectador ya ha sido testigo durante tres películas de la letal amenaza que suponen los dinosaurios, simplemente se muestra el nacimiento de uno de ellos, lo que ya de por sí sirve como antecedente del posible desastre.

Como secuela, más que ninguna otra entrega, Jurassic World incide mucho en el concepto de temporalidad. Se remarca a menudo que han pasado veinte años entre el intento de edificación del primer parque fallido y este segundo intento de éxito. El tiempo se utiliza como sinónimo de modernización, como si el fracaso del primer proyecto se debiera a la falta de recursos tecnológicos y la inadecuación histórica. Finalmente, la moraleja del relato explicita que esta premisa nunca ha sido cierta, y que la compleja adaptabilidad de humanos y dinosaurios en el mismo momento histórico siempre ha sido el auténtico dilema.

En relación a las referencias intertextuales explícitas entre ambos filmes, se producen múltiples alusiones que incrementan la sensación de complicidad con el espectador. A nivel iconográfico, se reutilizan escenificaciones y objetos muy conocidos para el público: desde la puerta de entrada principal del parque, hasta la cabra viva para alimentar al Tyrannosaurus Rex, pasando por primeros planos del mosquito encapsulado en el ámbar o la aparición de Mr. Adn, el dibujo animado que se empleaba en el primer parque para explicar el renacimiento de los dinosaurios; asimismo, algunas secuencias se reproducen casi como calco: el conocido primer plano del ojo del dinosaurio cuando está acechando a su presa, el uso de los coches para ocultarse de su vista, la persecución dinosaurio/coche o la reproducción de la lucha final, junto al edificio principal del parque, donde Zach, Gray, Claire y Owen se protegen entre sí ante la amenaza de los Velociraptores. Así pues, en gran medida el atractivo del presente filme se consigue mediante su identificación como «palimpsesto», siendo completamente reconocible el legado de Parque Jurásico. 
Por otro lado, la continuidad del discurso se mantiene mediante alusiones de guion muy concretas, nombrando a John Hammond en varias ocasiones, repitiendo su famoso mantra «sin reparar en gastos» e incluso introduciendo, en segundo plano, el libro escrito por el Dr. Malcom. En otros casos se produce una actualización del contenido original: los Jeep sobre raíles han sido sustituidos por las modernas giroesferas, que permiten una visita mucho más interactiva del parque, y los hologramas en tres dimensiones ocupan el lugar de los esqueletos de exhibición. Asimismo, la propia banda sonora del filme se escucha como un reajuste de la primera versión ${ }^{9}$, pues, aunque introduce variantes, se mantiene fiel a la mayor parte de los leitmotivs originales. Pero sin lugar a duda, la mayor complicidad se establece cuando se introducen objetos que directamente pertenecen al primer parque, lo que sucede cuando Zach y Gray encuentran el edificio desalojado del Jurassic World, cuyo hall, aunque muestre los estragos del abandono, se conserva prácticamente igual; allí descubren una de las cámaras de visión nocturna, así como de los viejos Jeep que consiguen reparar para volver al nuevo recinto. De ese modo, el antiguo parque les sirve como refugio a los niños, pudiendo sugerirse, desde una interpretación hermenéutica, que lo conocido y lo familiar (la primera película), se reutilizan para reconfortar al espectador.

Como «ficción de la repetición», Jurassic Word comparte muchos nexos temáticos con el producto original. Para empezar, ambas películas inciden en la necesidad de respetar y comprender la naturaleza más allá de la aparente superioridad que los humanos creen poseer. A pesar de la evolución tecnológica y las innumerables medidas de seguridad, se pone de manifiesto la incapacidad para controlar lo incontrolable, lo que demuestra que el dominio que creen tener los personajes es una simple ilusión. Asimismo, los humanos, en principio presentados como seres evolucionados y racionales, acaban comportándose como seres instintivos cuya mejor baza es la audacia, reconectando, a medida que avanza el metraje, con su lado más animal. Desde esta óptica, el personaje que mejor muestra este arco de transformación es la Doctora Dearing, presentada como un ser completamente civilizado, preocupada únicamente por las cifras económicas del parque de atracciones, y que a medida que avanza el filme, va reconectando con su faceta más salvaje; por un lado, la presencia de sus sobrinos en las instalaciones, y por otro, la observación de los dinosaurios como seres vivos cuando ve los estragos que hace el Indominus Rex, la hacen volverse más consciente de su propia naturaleza. Visualmente, esto se evidencia a través de dos escenas clave: la primera, en la que convence a Owen de que está lista para salvar a sus sobrinos cruzando la jungla, anudándose la camisa y asemejándose simbólicamente a la Doctora Ellie Sattler por el atuendo; la segunda secuencia es aquella en la que corre delante del Tyrannosaurus Rex con una bengala encendida para conducirlo a la lucha final contra el Indominus Rex.

La confrontación que los personajes sufren entre su condición más humana y su faceta más animal también se traduce en la transformación de sus prioridades a lo largo de los filmes. En ambos ejemplos, es la avaricia humana la que desencadena la catástrofe, pues tanto el programador del parque Dennis Nedry (Wayne Knight) en Parque Jurásico como la Doctora Dearing en esta entrega están únicamente preocupados, en un principio, por el beneficio económico, lo que deriva en una serie de decisiones erróneas; no obstante, esta motivación se vuelve superflua cuando la prioridad es la supervivencia, conectando con su naturaleza como seres vivos.

\section{ConClusiones}

El análisis comparativo realizado entre los dos filmes evidencia conexiones, temáticas y estructurales, que sobrepasan la noción tradicional de secuela. Como prolongación diegética, la vinculación

\footnotetext{
${ }^{9}$ No obstante, la banda sonora de Parque Jurásico está compuesta por John Williams y la de Jurassic World por Michael Giacchino. 
más importante que se refleja es la temporalidad, haciendo hincapié en cómo el paso de los años ha hecho posible la realización del sueño utópico del primer parque; esta incidencia en el gran desarrollo tecnológico actual refleja autorreflexividad sobre el propio discurso, porque está expresando que los medios han evolucionado tanto que es posible contar la misma historia, o al menos una muy similar, de forma completamente virtual. Es significativo además cómo Jurassic Word no se sirve del spin-off como estrategia narrativa de prolongación del discurso, pues lo cierto es que el universo creado por Steven Spielberg tiene la suficiente identidad temática, visual y sonora como para no tener que rescatar antiguos personajes que den continuidad a la historia, tal y como ocurría en las otras dos secuelas. Las alusiones directas, a través de la repetición de escenas, las referencias en los diálogos y la similitud en la estructura del guion son suficientes para asegurar la complicidad por parte del espectador.

Desde una perspectiva formal, Jurassic World no es un remake, pues su concepción como secuela impide que pueda catalogarse estrictamente como una nueva versión del relato original. Sin embargo, el espectador diferencia esta nueva entrega de las anteriores secuelas, así como puede captar las numerosas similitudes entre Parque Jurásico y Jurassic World, tales como la arquitectura narrativa, la repetición de la función de los personajes o la reiteración de escenas, objetos y motivos temáticos. En este sentido, el embrionario concepto de recuela, empleado por los internautas en las redes sociales, sirve específicamente para designar prolongaciones diegéticas con un alto nivel de autoconciencia con respecto a un texto original que es venerado. No obstante, más que asociarse a estructuras narrativas, el término se encuentra tan vinculado al bagaje del público que su uso se ve limitado por su conocimiento, es decir, que, si la audiencia no ha visto el producto madre, no captará las conexiones entre los textos, por lo que el empleo de recuela se adscribe a contextos de recepción específicos. Aunque Jurassic World es una propuesta audiovisual independiente, que puede consumirse de forma separada como película de aventuras, adquiere su auténtica significación si se conoce el discurso completo. En consecuencia, las capas complejas de sentido y asociación de ideas sobre las que argumenta Henry Jenkins en relación a la formación del «palacio de la memoria» solo adquieren conciencia, en el caso de esta película, si el espectador ha visto previamente Parque Jurásico, puesto que su experiencia será mucho más satisfactoria y completa. La recuela, pues, no se presenta como una noción atemporal ni absoluta, sino que, en principio, se adscribe a una tendencia de producción histórica concreta y a ciertos hábitos de consumo, por lo que se precisa la observación de nuevos casos que ratifiquen su validez para confirmarse en un futuro como concepto académico estable.

A modo de conclusión, se debe mencionar cómo esta película ofrece un final muy simbólico, pues la derrota del nuevo dinosaurio híbrido por parte del mítico Tyrannosaurus Rex funciona como perfecta metáfora del homenaje consciente que esta secuela hace al primer filme. Mediante este desenlace se ejemplifica cómo, a pesar del increíble desarrollo digital que se ha producido en el nuevo milenio y que es verificable en Jurassic World, esta nueva entrega nunca podrá superar al producto original, ya que Parque Jurásico sigue estando muy presente en el imaginario colectivo de varias generaciones.

\section{BIBLIOGRAFÍA}

Balló, J. y Pérez, X. (2005). Yo ya he estado aqui: ficciones de la repetición. Barcelona, España: Anagrama.

Bremond, C. (1970). La lógica de los posibles narrativos. En Barthes et al., Análisis estructural del relato (pp. 87-110). París, Francia: Editorial Tiempo Contemporáneo.

Casetti, F. y Di Chio, F. (1991). Cómo analizar un film. Barcelona, España: Paidós.

Collins, J. (1992). Postmodernism and Television. En Allen, R. C. (ed.), Channels of Discourse, Reassembled (pp. 327-353). London, England: Routledge. 
Darley, A. (2000). Visual Digital Culture. Surface Play and Spectacle in New Media Genres. London, England: Routledge.

Eco, U. (2012). De los espejos y otros ensayos. DeBolsillo [Edición electrónica para Kindle].

Genette, G. (1989). Palimpsestos. La literatura en segundo grado. Madrid, España: Taurus.

Gwenllian-Jones, S. \& Pearson, R. E. (eds.). (2004). Cult Television. Minneapolis, USA: University of Minnesota Press.

Isaacs, B. (2008). Toward a New Film Aesthetic. London, England: Continuum.

Jenkins, H. (2007). The WOW Climax. Tracing the Emotional Impact of Popular Culture. New York, USA: New York University Press.

Lipovetsky, G., y Charles, S. (2006). Los tiempos hipermodernos. Barcelona, España: Anagrama.

Mittell, J. (2004). Genre and Television. From Cop Shows to Cartoons in American Culture. New York, USA: Routledge.

Pujadas, E. (2011). La televisión de calidad. Contenidos y debates. Bellatera, Barcelona, Castellón de la Plana y Valencia, España: Aldea Global.

Riambau, E. (2011). Hollywood en la era digital. De Jurassic Park a Avatar. Madrid, España: Cátedra.

Sánchez-Escalonilla, A. (2004). Steven Spielberg. Entre Ulises y Peter Pan. Madrid, España: Dossat.

Stam, R. (2001). Teorías del cine. Barcelona, España: Paidós.

Tryon, C. (2013). Reboot cinema. Convergence: The International Journal of Research into New Media Technologies. doi: $10.1177 / 1354856513494179$

Verevis, C. (2006). Film remakes. Edinburgh, Scotland: Edinburgh University Press.

Visa Barbosa, M. (2008). El placer «trágico» de volver a ver un film: el saber superior del espectador en segundos visionados, remakes, flah-backs y adaptaciones de hechos reales. Revista de Comunicación Vivat Academia, n. ${ }^{\circ}$ 96, Año XI, 1-15. doi: http://dx.doi.org/10.15178/va.2008.96.1-15.

Wolf, M. (1987). La investigación de la comunicación de masas. Barcelona, España: Paidós.

\section{Fonseca, Journal of Communication}

